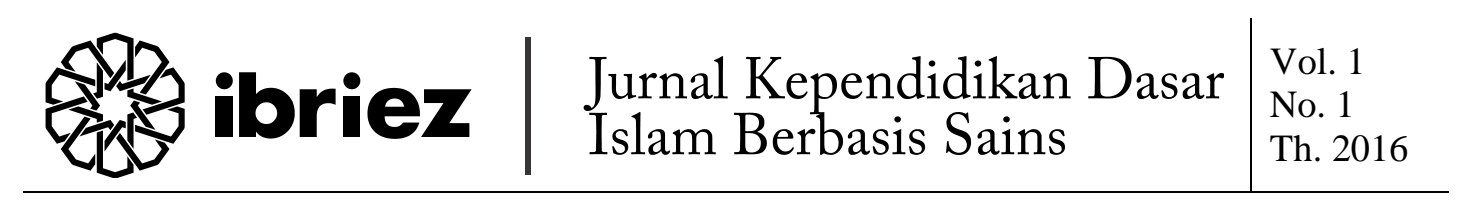

\title{
Scaffolding dalam Menyelesaikan Permasalahan KPK dan FPB
}

\author{
Sofwan Hadi \\ Tarbiyah STAIN Ponorogo \\ sofwan@stainponorogo.ac.id
}

Abstrak

\begin{abstract}
Pembelajaran dalam kelas berisi siswa yang heterogen pada kemampuan memahami materi, yang memerlukan perlakuan berbeda antara siswa dalam kelas. Siswa yang tidak mampu mengkosntruksi pemahaman materi KPK dan FPB dalam pembelajaran perlu mendapat Scaffolding yang cukup oleh Guru. Penelitian ini menggunakan metode Kualitatif Deskriptif untuk menganalisaScaffolding yang diberikan. Pendekatan Scaffolding menggunakan pendekatan Anghiheleri. Penelitian ini menghasilkanScaffolding bisa dilakukan dengan dua jenis. Pertama dengan penguatan materi, dan kedua dengan penguatan dalam kegiatan pembelajaran.
\end{abstract}

Kata Kunci: kesulitan belajar; scaffolding; anghiheleri; kelipatan persekutuan terkecil.

\section{PENDAHULUAN}

$$
\text { Setiap orang hakikatnya }
$$
mempunyai permasalahan. Begitujuga dalam kajian pembelajaran matematika. Siswa harus bisa mengatasi permasalahan yang dihadapi. Menurut Kurniasih ${ }^{1}$ salah satu cara untuk mengatasi permasalahan adalah dengan berpikir kritis. Karena dengan berpikir kritis siswa dapat menelaah permasalahan yang dihadapi,mencari dan memilih penyelesaian yangtepat, logis, dan bermanfaat. Berpikir kritis dalam permasalahan matematika me-ngajak

\footnotetext{
${ }^{1}$ Ary Woro Kurniasih, "Scaffolding Sebagai Alternatif Upaya Meningkatkan Kemampuan Berpikir Kritis Matematika," Kreano, Jurnal Matematika Kreatif-Inovatif 3, no. 2 (12 Desember 2012): 113-24, doi:10.15294/kreano.v3i2.2871.g2971.
}

siswa untuk menghayati permasalahan secara utuh, kemudian siswa belajar untuk mencari alternatif dalam penyelesaiannya. Peran guru sangat penting saat ini saat siswa kesulitan mencari penyelesaian masalah matematika guru harus siap memberikan bantuan untuk menyelesaikannya.

Batuan yang diberikan oleh guru dalam kegiatan pembelajaran dikenal dengan istilah Scaffolding. Pengetahuan tentang konsep Scaffolding diperlukan guru agar pemahaman konsep siswa bisa tercapai sesuai dengan target pembelajaran. Hasil penelitian Tyas $^{2}$ men-

\footnotetext{
${ }^{2}$ Sabta Wiyasaningtiyas, "Diagnosis Kesulitan dalam Pemecahan Masalah Teorema Pythagoras dan Pemberian Scaffolding Pada Siswa Kelas VIII G SMP Negeri 2 Malang," SKRIPSI Jurusan Matematika - Fakultas MIPA
} 
jelaskan pemberian Scaffolding dalam pemahaman Terorema Phytagoras bisa dilakukan dengan pemberian petunjuk letak kesulitan dalam pemahaman materi. Bantuan yang diberikan oleh guru dalam tiap materi berbeda bergantung tingkat kesulitan yang dialami oleh siswa. Menurut Zahra ${ }^{3}$ Scaffolding yang diberikan oleh guru sebaiknya berupa arahan yang digunakan untuk membantu siswa dalam meningkatkan Zone Proximal Development siswa. Scaffolding yang berlebihan kurang baik dalam kegiatan pembelajaran. Karena siswa tidak terlatih dalam mengkonstruksi pemikiran sendiri ketika menyelesaikan masalah matematika. Menurut Trajuningsih ${ }^{4}$, guru dituntut cermat dalam pemberian scaffolding pada saat pengamatan kesalahan siswa. Oleh karena itu scaffolding yang baik dari guru merupakan salah satu faktor kegiatan pemahaman siswa bisa meningkat.Scafollding menurut Sofwan ${ }^{5}$ merupakan salah satu penyebab proses

UM 0, no. 0 (10 Agustus 2012), http://karyailmiah.um.ac.id/index.php/matematika/article/ view/22898.

${ }^{3}$ Zahra Chairani, "Scaffolding dalam Pembelajaran Matematika," Math Didactic: Jurnal Pendidikan Matematika 1, no. 1 (30 April 2015),

http://jurnal.stkipbjm.ac.id/index.php/math/ar ticle/view/12.

${ }^{4}$ Endah Trajuningsih, "Proses Berpikir Matematis Siswa SMAN 8 Malang Dalam Menyelesaikan Masalah Matematika dan Scaffolding," DISERTASI dan TESIS Program Pascasarjana UM 0, no. 0 (14 Januari 2015), http://karyailmiah.um.ac.id/index.php/disertasi/article/vie w/37245.

${ }^{5}$ Sofwan Hadi, "Proses Konstruksi Pengetahuan Siswa Pada Pembelajaran Perbandingan Trigonometri" (Universitas Negeri Malang, 2008). konstruk siswa bertambah. Karena dengan adanya Scafollding yang dilakukan oleh guru Zona Proximal Development siswa juga bisa bertambah. Oleh karena itu Scafollding yang dilakukan oleh guru memiliki peranan penting agar pemahaman siswa bisa dikonstruksi dengan baik.

\section{METODE PENELITIAN}

Metode penelitian yang dilakukan oleh peneliti dalam riset ini adalah kualitatif. Desain penelitian kualitatif terdiri dari tiga model, yaitu format deskriptif, format verifikasi, dan format grounded research. Pelitian menggunkan metode kualitatif dengan desain deskriptif, yaitu penelitian yang memberi gambaran secara cermat mengenai individu ataukelompok tertentu tentang keadaan dan gejalayang terjadi ${ }^{6}$. Pada penelitian ini proses scaffolding individu siswa akan dideskripsikan dan juga akan dikaji secara dalam.

Pada teknik penelitian ini peneliti menentukan subjek penelitian sebanyak 3 orang. Pemilihan subjek ini dilakukan dengan pertimbangan memilih subjek yang gaya berfikirnya unik saat memahami materi KPK dan FPB. Ketiga subjek penelitianini selanjutnya akan diberikan kode S1, S2 dan S3. Pemilihan subjek juga mepertimbangkan kemampuan komunikasi. Hal ini agar ketika penggalian informasi tentang proses berfikir bisa terserap dengan sebaik baiknya, sehingga data yang

\footnotetext{
${ }^{6}$ Koentjaraningrat, Metode-metode Penelitian Masyarakat (Jakarta: Gramedia, 1991).
} 
diperoleh dari wawancara bisa lebih akurat dan bisa tergali secara mendalam.

Instrumen yang paling penting dalam penelitian kualitatif adalah peneliti itu sendiri ${ }^{7}$.Hal itu karena peneliti sangat berperan dalam keseluruhan proses penelitian, termasuk dalam pengumpulan data. Oleh karena itu pada penelitian kualitatif peneliti harus responsif, dapat menyesuaikan diri, menekan keutuhan, mendasarkan diri atas perluasan pengetahuan, memproses data secepatnya, memanfaatkan kesempatan untuk mengklasifikasikan dan mengikhtisarkan, dan mencari respon yang tidak lazim. Penelitian ini juga menggunakan instrumen pengamatan dan wawancara. Pengamatan ini digunakan untuk mencatat hal-hal selama kegiatan berlangsung. Kesulitan pengamatan karena pada saat penelitian harus siap sewaktu-waktu, karena informasi data pengamatan bisa tidak bisa ditentukan kapan dibutuhkan.

Tahapan scaffolding dilakukan dengan tahapan Angihileri ${ }^{8}$. Adapun tahapan Angihileri untuk mendukung kegiatan pembelajaran sebagai berikut :

Tahap1: Ketentuan Lingkungan

Tahap2: Menjelaskan, mereviewdanmerekonstruksi

Tahap 3: Membangun konsep berfikir.

Tahapan Angihileri digunakan untuk menjelaskan proses yang dilakukan dalam

${ }^{7}$ Lexy J. Moleong, Metodologi Penelitian Kualitatif (Bandung: Remaja Rosda Karya, 1999). ${ }^{8}$ Julia Anghilery, "Scaffolding practices that enhance mathematics learning," Journal of Mathematics Teacher Education 9, no. 1 (2006): 33-52. penelitian. Tahap 1 dimulai dari penyiapan kelas, penyiapan ini meliputi pengorganisasian dan penyiapan alat peraga. Tahap 2 dilaksanakan dengan memberikan bantuan dengan agar siswa dapat memahami, meriview penjelasan guru dan mengkonstruksi pemhaman siswa. Tahap 3 siswa mampu membangun konsep berfikir sendiri tentang pemahaman materi yang diterimanya.

\section{PEMBAHASAN}

Pada penelitian ini akan diuraikan tahapan-tahapan dalam menganalisa proses scaffolding yang dilakukan oleh guru.

\section{A. Identifikasi permasalahan pembe- lajaran}

Pada tahap ini peneliti melakukan kegiatan untuk wawancara dan tes untuk mengetahui sejauh mana kesulitan siswa dalam memahami permasalahan KPK dan FPB. Identifikasi ini dilakukan pada ketiga subjek penelitian. Pemahaman siswa dipetakan dengan menggunakan Mind Mapping. Mustaqim ${ }^{9}$ efektif menggunakan konsep mind mapping untuk menjelaskan proses pemahaman yang ada pada siswa. Pada mind mappig pemahaman yang diberikan garis putus-putus berarti pemhaman siswa tentang materi tersebut belum dikuasai oleh siswa sepenuhnya. Panah pada mind mapping menunjukkan proses pengetahuan yang dikuasi digunakan untuk mengkonstruksi pengetahuan yang selanjutnya.

\footnotetext{
${ }^{9}$ Mustaqim Mustaqim, "Scaffolding process Based on Diagnosis Students Difficulties in Solving Linear Program by Using Mapping Mathematic," Jurnal Pendidikan Sains (JPS) 1, no. 1 (2014): 72-78.
} 
Identifikasi awal S1 diperoleh data sebagai berikut. S1 sama sekali belum memahami tentang konsep KPK dan FPB. S1 belum memahami konsep KPK dan FPB pada saat pemahaman definisi Kelipatan dan Faktor. S1 dalam pemahaman faktor merasa penjelasan kurang baik karena konsep faktor dan kelipatan sulit dibedaakan. Selain itu ketrampilan dalam melakukan operasi pemfaktoran dan operasi hitung bilangan bulat dari S1 dirasa kurang baik. Hal ini mengakibatkan ketika memahami tentang langkahlangkah pengerjaan KPK dan FPB, S1 merasa kesulitan.

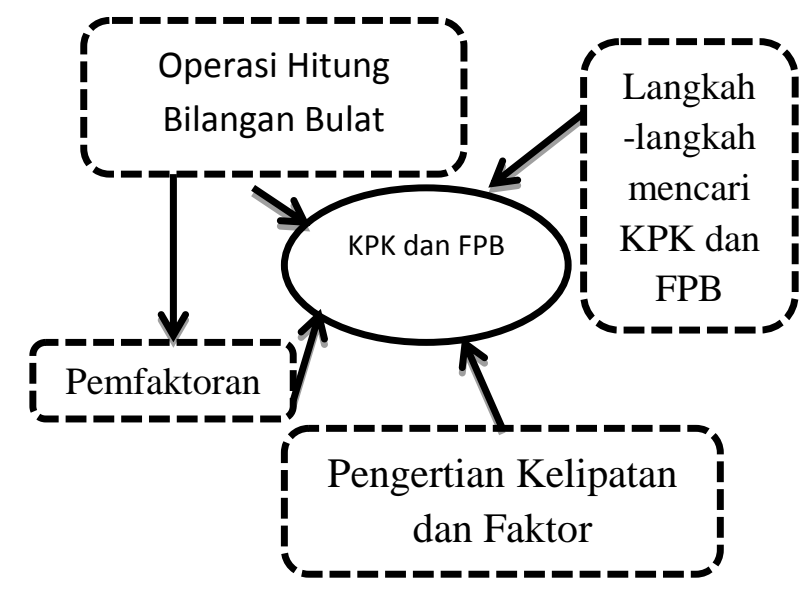

Gambar 1. Pola pemahaman materi S1

S2 mengalami kesulitan tentang pengerjaan KPK dan FPB akibat menggunakan strategi yang masih sdikit. Strategi yang dikuasainya menggunakan pohon faktor. Itupun S2 masih merasa kebingungan dengan langkah-langkah pemilihan pangkat faktor yang harus dikalikan pada penyelesaian KPK dan FPB dengan metode pohon faktor. Ketrampilan perhitungan S2 sudah bagus, S2 bisa mengoperasikan operasi hitung bilangan dan melakukan operasi perpangkatan.

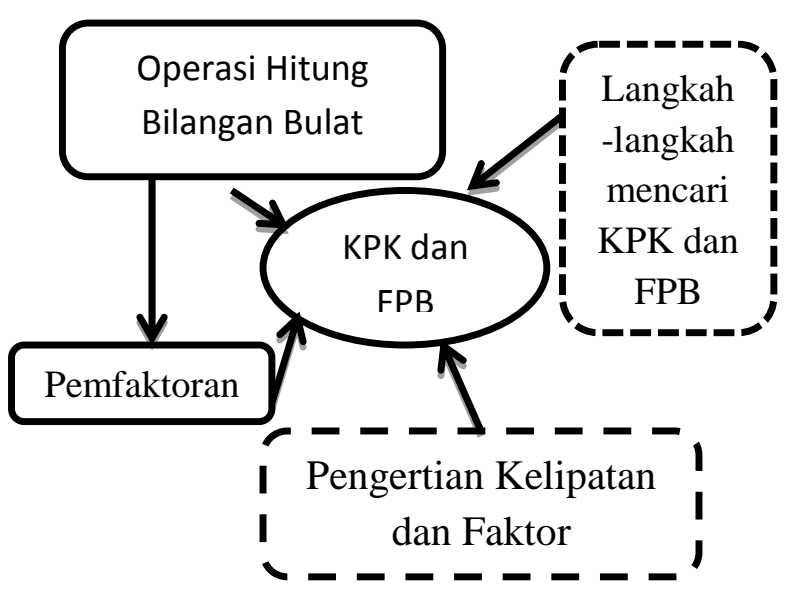

Gambar 2. Pola pemahaman S2

S3 mengalami kesulitan dalam pengertian Kelipatan dan Faktor. S3 mengalami kesulitan pada saat pembelajaran dia tidak memperhatikan penjelasan guru. Selain itu langkahlangkah dalam menentukan KPK dan FPB juga belum dikuasai dengan baik. Kesulitan memahami materi karena menurut S3 kelas terlau ramai sehingga konsep pemahaman materi belum dipahami dengan baik.

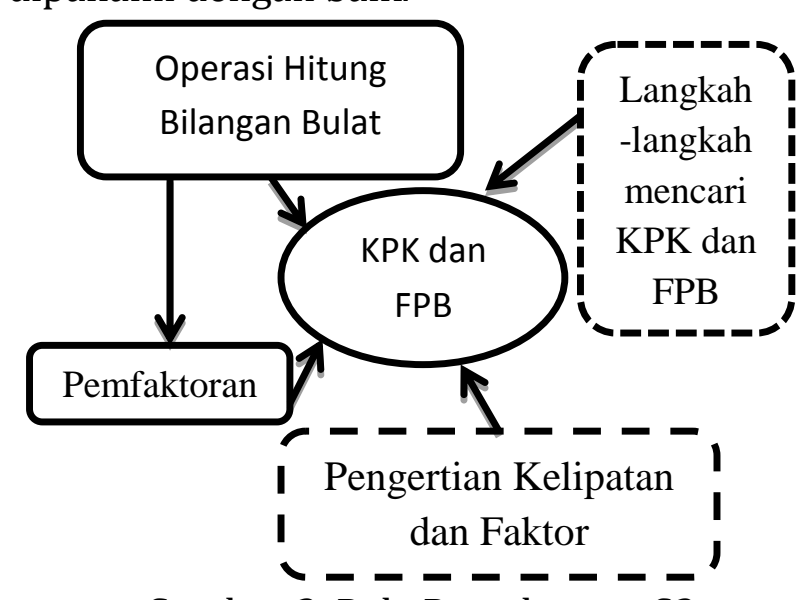

Gambar 3. Pola Pemahaman S3

\section{B. Proses Scaffolding}

Scafollding yang dilakukan menggunakan metode Angihilery ${ }^{10}$. Kegiatan yang dilaksanakan akan menggunakan 3

\footnotetext{
${ }^{10}$ Anghilery, "Scaffolding practices that enhance mathematics learning."
} 
tahapan berdasarkan identifikasi pemahaman siswa.

Tahap Pertama. Identifikasi pemahaman siswa diperloleh siswa kesulitan pemahaman karena kondisi kelas yang kurang kondusif. Sehingga S3 merasa kesulitan dalam mengkonstruksi pemahaman yang dia peroleh. Pada tahapan ini Scafollding yang diberikan berupa pembentukan kelompok kecil. Pembentukan kelompok ini diharapkan bisa meningkatkan konsentrasi siswa dalam menerima materi yang diberikan oleh guru. Pembentukan kelompok ini juga didesain dengan adanya siswa yang pintar dan mampu berkomunikasi yang merata. Sehingga ketika ada kesulitan pemahaman materi yang diberikan oleh guru siswa bisa berdiskusi dengan rekan sejawat.

Tahap Kedua. Tahapan ini ada 3 kegiatan yang dilaksanakan. Scaffolding yang diberikan kesiswa berbeda beda sesuai dengan tingkat kesulitan pembelajaran. Manurut Abadi 11 pemberian bantuan dalam proses Scaffolding ini tidak boleh terlalu banyak. Karena hal itu akan mengakibatkan siswa tidak mandiri dalam proses konstruksi pemahaman siswa. Adapun kegiatan kedua dilakukan sebagai berikut :

1. Merencanakan

S1 pada kegiatan merencanakan memerlukan scaffolding yang agak banyak dibandingkan subjek yang lain. S1 diberikan soal-soal secara intensif

\footnotetext{
${ }^{11}$ Agung Prasetyo Abadi, “Diagnosis Kesulitan Siswa Dalam Menyelesaikan Masalah Geometri-PISA Melalui Pemetaan Kognitif dan Upaya Mengatasinya dengan Scaffolding" (Universitas Negeri Malang, 2014), http://karyailmiah.um.ac.id/index.php/disertasi/article/view/361 18.
}

berkaitan dengan operasi hitung pecahan dan pemfaktoran. Soal yang diberikan pada S1 bertahap dari soal yang mudah sampai level yang sulit berkaitan dengan operasi hitung bilangan bulat. Kesulitan S1 ketika melakukan operasi hitung perpangkatan dengan basis yang berbeda. Terkadang masih salah basisnya ikut dikalikan. Selain itu kesulitannya ketika menyederhanakan bilangan perpangkatan dengan basis bilangan prima. Saat diberikan permasalahan materi KPK dan FPB S1 kesulitan memahami langkahlangkah pengerjaan. Scaffolding yang diberikan dengan menjelaskan dengan perlahan dan pembimbingan yang intensif dengan mengajukan pertanyaan prosedur langkah.

S2 pada saat penjelasan kurang memahami tentang operasi kelipatan dan faktor. Scaffolding diberikan dengan memberikan contoh tentang kelipatan dan faktor. Selain itu juga dipantau dengan memberikan permasalahan tentang kelipatan serta faktor. Saat penjelasan langkah dengan pohon faktor S2 merasa kesulitan untuk memfaktorkaan. Guru menyajikan metode selain pohon faktor yaitu menggunakan metode sisir. S2 ternyata lebih cepat memahami langkahlangkah menggunakan metode sisir.

S3 pada tahap merencanakan dipasangkan dengan teman yang pandai berkomunikasi. Dalam tahap kemampuan merencanakan ketika ada penjelasan yang belum dipahami S3 senantiasa berkomunikasi dengan teman sebaya. Guru memberikan latihan untuk mengecek sejauh mana kemampuan merencanakan subjek.

2. Mereview 
Pada ahap ini subjek penelitian diamati tentang cara mereview suatu permasalahan. Hal ini digunakan sebagai bahan tindakan untuk pemberian scaffolding agar sesuai dengan kemampuan siswa.

S1 mereview pemahaman setelah mendengarkan penjalasan guru. Ketika memperoleh permasalahan tentang KPK dan FPB, S1 merasa kurang percaya diri tentang konsep yang dipahami. Scaaffolding dilakukan dengan memberikan senyuman dan pujian. S1 juga terlihat kesulitan dalam tahapan langkah-langkah pengerjaan KPK dan FPB. Kesulitan ini karena S1 masih belum membedakan tahapan KPK dan FPB dengan metode pohon faktor. Scaffolding dengan memberikan menganalisa perbedaan tahapan KPK dan FPB pada tahapan pohon faktor.

S2 dan S3 tahapan mereview mendapat bantuan dari teman sebaya. S2 mencoba berbagai strategi dalam mengerjakan KPK dan FPB. Sedangkan S3 ketika ada langkah yang masih belum memahami berinteraksi dengan temannya. S3 sesekali bertanya kepada guru untuk menegaskan pemahaman yang didapat hasil diskusi.

3. Merekonstruksi

S1 melakukan konstruksi pemahaman KPK dan FPB dengan melatih pemahaman operasi hitung bilangan bulat. Konsep ini dikonstruksi dengan melatih berulangulang operasi bilangan bulat. Pada tahap menentukan operasi KPK dan FPB S1 merasa bingung menentukan faktor yang dikalikan. Hal ini bisa dilihat dari coretcoretan kurang percaya diri dalam melakukan perhitungan. KPK dan FPB dikonstruksi dengan bantuan yang diberikan guru berupa penguatan dan diskusi dengan teman.

S2 melakukan konstruksi dengan melakukan pemilihan langkah yang sekiraanya sudah dipahami. Pada awal mengerjakan S2 menggunakan menggunakan metode Pohon Faktor untuk menentukan KPK dan FPB. Tetapi konsep itu kesulitaan menentukan urutan langkah pengerjaan pada tahapan menentukan faktor dengan pangkat terbesar dan terkecil. S2 menggunakan metode sisir yang tidak memerlukan faktor dan urutan. Selain itu dalam tahap konstruksi juga masih ragu-ragu dalam menggunakannya memerlukan penguatan langkah. Sehingga sering bertanya kapada guru dan teman sebayanya.

S3 dalam proses konstruksi memerlukan bantuan teman. Teman sebaya menurut S3 lebih nyaman untuk diajak komunikasi. Peran guru dalam memilihkan teman yang bisa berkomunikasi sangat mendukung kegiatan konstruksi pemahaman materi. Teman sebaya yang dipilih memiliki pola pemikiran yang sama dengan S3. Teman sebaya menjelaskan langkah-langkah urutan pengerjaan dan membantu ketika ada kesulitan dalam konstruksi pemahaman.

\section{SIMPULAN}

Scafolding dalam pembelajaran KPK dan FPB bisa dilakukan dengan beberapa pendekatan. Pada tingkat kesulitan siswa mengalami kesulitan mengkonstruksi KPK dan FPB dikarenakan beberapa faktor. Siswa mengalami kesulitan di materi 
pembelajaran saat menggunakan langkahlangkah pengerjaan KPK dan FPB. Selain itu siswa punya kendala ketika mengkonstruksi karena kurang memahami proses mengoperasikan bilangan. Pada tahapan ini peran guru Scaffolding dengan menyiapkan pemahaman siswa sebelum menerima. Tahapan ini bisa dilakukan dengan memberikan drill atau remedial terhadap siswa yang kurang pemahaman materinya.

Scafollding pada penorganisasian kelas juga perlu dilakukaan oleh guru. Karena ada siswa yang mengkonstruksi KPK dan FPB memerlukan bantuan lingkungan luar. Salah satunya dengan membuat kelompok kecil. Ada baiknya dalam membentuk kelompok kecil perlu dipilihkan teman sebaya yang bisa mudah berkomunikasi dengan siswa yang mengalami kesulitan belajar. Teman sebaya bisa sebagai tempat pertama bertanya ketika siswa mengalami kesulitan pembelajaran. Peran guru adalah memahami karakteristik siswa yang dekat dengan siswa bermasalah.

Suatu strategi penyelesaian KPK dan FPB sebaiknya disuguhkan dengan beberapa strategi. Karena siswa yang diajarkan dengan menggunakan pohon faktor merasa kesulitan ketika menerima pemahaman itu. Peran guru menyediakan berbagai alternatif pengerjaan KPK dan FPB selain pohon faktor. Dalam penelitian ini menggunakan metode sisir sebagai metode pendamping dalam scafollding konstruksi pemahaman siswa.

Scaffolding perlu diteliti lebih lanjut pada materi yang lain. Pada materi KPK dan FPB, scaffolding diteliti pada kasus yang umum. Perlu diteliti dalam kajian psikologi siswa yang khusus, karena siswa dalam kelas yang heterogen banyak karakterisitik siswa yang unik yang memerlukan scaffolding dari guru. Pemahaman scaffolding perlu dipahami guru untuk mengenal karakteristik siswa dan bahan informasi untuk mendesai pembelajaran yang sesuai kebutuhan siswa.

\section{DAFTAR PUSTAKA}

Abadi, Agung Prasetyo. “Diagnosis

Kesulitan Siswa Dalam

Menyelesaikan Masalah Geometri-

PISA Melalui Pemetaan Kognitif

dan Upaya Mengatasinya dengan

Scaffolding." Universitas Negeri

Malang, 2014. http://karya-

ilmiah.um.ac.id/index.php/disertas i/article/view/36118.

Anghilery, Julia. "Scaffolding practices that enhance mathematics learning." Journal of Mathematics Teacher Education 9, no. 1 (2006): 33-52.

Chairani, Zahra. "Scaffolding dalam Pembelajaran Matematika." Math Didactic: Jurnal Pendidikan Matematika 1, no. 1 (30 April 2015).

http://jurnal.stkipbjm.ac.id/index. $\mathrm{php} / \mathrm{math} /$ article/view/12.

Koentjaraningrat. Metode-metode Penelitian Masyarakat. Jakarta: Gramedia, 1991.

Kurniasih, Ary Woro. "Scaffolding Sebagai Alternatif Upaya Meningkatkan Kemampuan Berpikir Kritis Matematika." Kreano, Jurnal Matematika Kreatif-Inovatif 3, no. 2 (12 Desember 2012): 113-24. doi:10.15294/kreano.v3i2.2871.g2 971.

Moleong, Lexy J. Metodologi Penelitian Kualitatif. Bandung: Remaja Rosda Karya, 1999. 
Mustaqim, Mustaqim. "Scaffolding process

Based on Diagnosis Students

Difficulties in Solving Linear

Program by Using Mapping

Mathematic." Jurnal Pendidikan

Sains (JPS) 1, no. 1 (2014): 72-78.

Sofwan Hadi. "Proses Konstruksi

Pengetahuan Siswa Pada

Pembelajaran Perbandingan

Trigonometri." Universitas Negeri

Malang, 2008.

Trajuningsih, Endah. "Proses Berpikir

Matematis Siswa SMAN 8 Malang

Dalam Menyelesaikan Masalah

Matematika dan Scaffolding."

DISERTASI dan TESIS Program

Pascasarjana UM 0, no. 0 (14

Januari 2015). http://karya-

ilmiah.um.ac.id/index.php/disertas

i/article/view/37245.

Wiyasaningtiyas, Sabta. "Diagnosis

Kesulitan dalam Pemecahan

Masalah Teorema Pythagoras dan

Pemberian Scaffolding Pada Siswa

Kelas VIII G SMP Negeri 2 Malang."

SKRIPSI Jurusan Matematika -

Fakultas MIPA UM 0, no. 0 (10

Agustus 2012). http://karya-

ilmiah.um.ac.id/index.php/matema

tika/article/view/22898. 